\title{
Design and synthesis of concentration gradient Prussian blue analogues
}

SuKyung Jeon, Carissa H. Li, Daniel R. Talham

Department of Chemistry, University of Florida, Gainesville, FL 32611-7200, Unites States

Corresponding author: Daniel R. Talham

Phone: 352-392-9016

E-mail: talham@chem.ufl.edu 


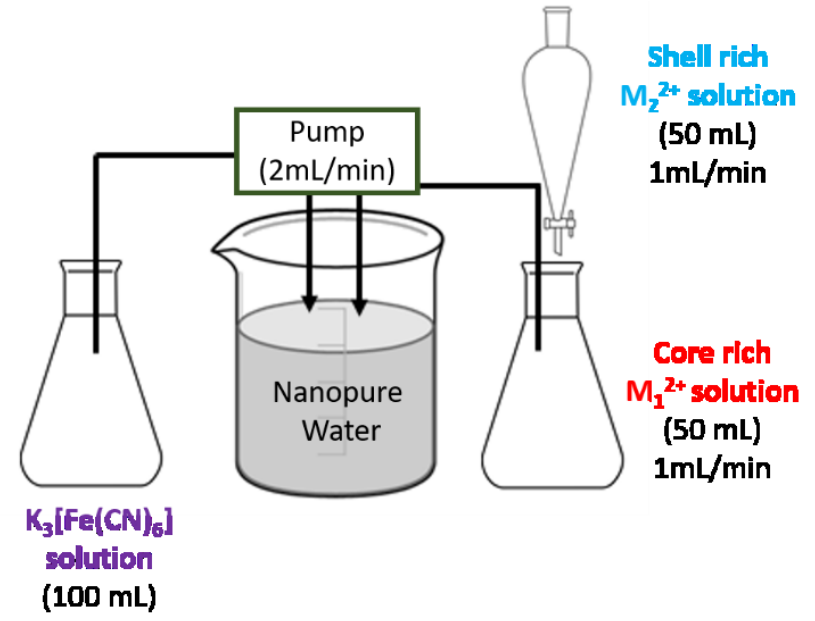

Scheme S1. Illustration of the experimental set up for the synthesis of concentration gradient PBA particles.

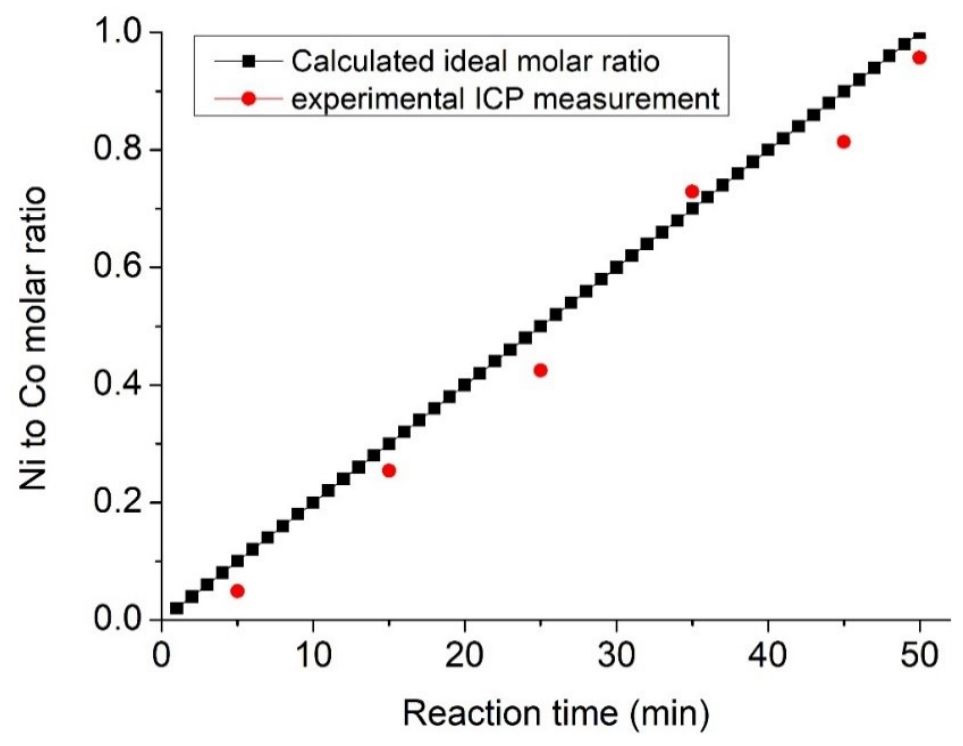

Figure S1. The Ni to Co molar ratio in g-CoNi[Fe $\left.(\mathrm{CN})_{6}\right]$ particle as a function of precursor addition time. The black dotted line is the programmed addition of ions during the synthesis. The red solid circles represent experimental ICP data from product collected at different intervals during the addition. 


\begin{tabular}{|c|c|c|c|c|}
\hline & & Sample & Average particle size $(\mathrm{nm})$ & Lattice constants (Å) \\
\hline \multirow{3}{*}{$\begin{array}{c}\text { Series } 1 \\
\text { (Single phase) }\end{array}$} & 1-1 & CoFe-PBA & $540+80$ & 10.31 \\
\hline & $1-2$ & NiFe-PBA & $170 \pm 30$ & 10.21 \\
\hline & $1-3$ & CuFe-PBA & $80 \pm 20$ & 10.15 \\
\hline $\begin{array}{c}\text { Series } 2 \\
\text { (core@shell) } \\
\end{array}$ & $2-1$ & CoFe-PBA@NiFe-PBA & $170 \pm 30$ & 10.28 and 10.23 \\
\hline \multirow{10}{*}{$\begin{array}{c}\text { Series } 3 \\
\text { (concentration } \\
\text { gradient) }\end{array}$} & $3-1$ & $\mathrm{~g}-\mathrm{CoNi}\left[\mathrm{Fe}(\mathrm{CN})_{6}\right]$ & $430 \pm 70$ & 10.26 \\
\hline & $3-2$ & g-CuNi[Fe $\left.(\mathrm{CN})_{6}\right]$ & $180 \pm 10$ & 10.17 \\
\hline & $3-3$ & $\mathrm{~g}-\mathrm{NiCu}\left[\mathrm{Fe}(\mathrm{CN})_{6}\right]$ & $100 \pm 20$ & 10.18 \\
\hline & 3-4 & $\mathrm{g}-\mathrm{CoNi}\left[\mathrm{Cr}(\mathrm{CN})_{6}\right]$ & $390 \pm 120$ & 10.51 \\
\hline & 3-5 & $\mathrm{g}-\mathrm{Ni}\left[\mathrm{Cr}(\mathrm{CN})_{6}\right]\left[\mathrm{Fe}(\mathrm{CN})_{6}\right]$ & $90 \pm 10$ & 10.35 \\
\hline & $3-6$ & $\mathrm{~g}-\mathrm{Co}\left[\mathrm{Fe}(\mathrm{CN})_{6}\right]\left[\mathrm{Cr}(\mathrm{CN})_{6}\right]$ & $600 \pm 60$ & 10.32 \\
\hline & $3-7$ & $\mathrm{~g}-\mathrm{CoNi}\left[\mathrm{Fe}(\mathrm{CN})_{6}\right]\left(4^{\circ} \mathrm{C}\right)$ & $210 \pm 30$ & 10.26 \\
\hline & $3-8$ & g-CoNi[Fe $\left.(\mathrm{CN})_{6}\right]\left(90^{\circ} \mathrm{C}\right)$ & $1100 \pm 170$ & 10.26 \\
\hline & $3-9$ & g-NiCo $\left[\mathrm{Fe}(\mathrm{CN})_{6}\right]\left(90^{\circ} \mathrm{C}\right)$ & $350 \pm 120$ & 10.26 \\
\hline & $3-10$ & $\mathrm{~g}-\mathrm{CoNi}\left[\mathrm{Fe}(\mathrm{CN})_{6}\right](\mathrm{Co}: \mathrm{Ni}=1: 3)$ & $250 \pm 90$ & 10.22 \\
\hline \multirow{2}{*}{$\begin{array}{c}\text { Series } 4 \\
\text { (core@gradient) }\end{array}$} & 4-1 & CoFe-PBA@g-CoNi[Fe(CN) $\left.)_{6}\right]$ & $780 \pm 120$ & 10.26 \\
\hline & $4-2$ & NiFe-PBA@g-NiCu[Fe(CN) 6$]$ & $120 \pm 20$ & 10.15 \\
\hline \multirow{4}{*}{$\begin{array}{c}\text { Series } 5 \\
\text { (solid solution) }\end{array}$} & $5-1$ & $\mathrm{CoNi}\left[\mathrm{Fe}(\mathrm{CN})_{6}\right]$ & $230 \pm 20$ & 10.27 \\
\hline & $5-2$ & $\mathrm{CoNi}\left[\mathrm{Fe}(\mathrm{CN})_{6}\right]$ & $170 \pm 20$ & 10.24 \\
\hline & $5-3$ & $\mathrm{CoNi}\left[\mathrm{Fe}(\mathrm{CN})_{6}\right](\mathrm{Co}: \mathrm{Ni}=3: 1)$ & $480 \pm 50$ & 10.28 \\
\hline & $5-4$ & $\mathrm{CoNi}\left[\mathrm{Fe}(\mathrm{CN})_{6}\right]\left(4^{\circ} \mathrm{C}\right)$ & $120 \pm 20$ & 10.24 \\
\hline $\begin{array}{c}\text { Series } 6 \\
\text { (core@gradient } \\
\text { @shell) }\end{array}$ & $6-1$ & $\begin{array}{c}\mathrm{CoFe}-\mathrm{PBA} @ \mathrm{~g}-\mathrm{Co}\left[\mathrm{Fe}(\mathrm{CN})_{6}\right] \mathrm{Ni}\left[\mathrm{Co}(\mathrm{CN})_{6}\right] \\
@ N i C o-P B A\end{array}$ & $720 \pm 50$ & 10.15 and 10.30 \\
\hline
\end{tabular}

Table S1. Particle dimensions and lattice constants for all the samples listed in the experimental section. Samples are written in shorthand notations defined in the manuscript. 


\begin{tabular}{|c|}
\hline Average particle size $(\mathrm{nm})$ \\
\hline $430 \pm 70$ \\
\hline $400 \pm 50$ \\
\hline $440 \pm 70$ \\
\hline
\end{tabular}

Table S2. Average particle size of $\mathrm{g}-\mathrm{CoNi}\left[\mathrm{Fe}(\mathrm{CN})_{6}\right]$ in three individual syntheses to show relatively similar size from each batch.
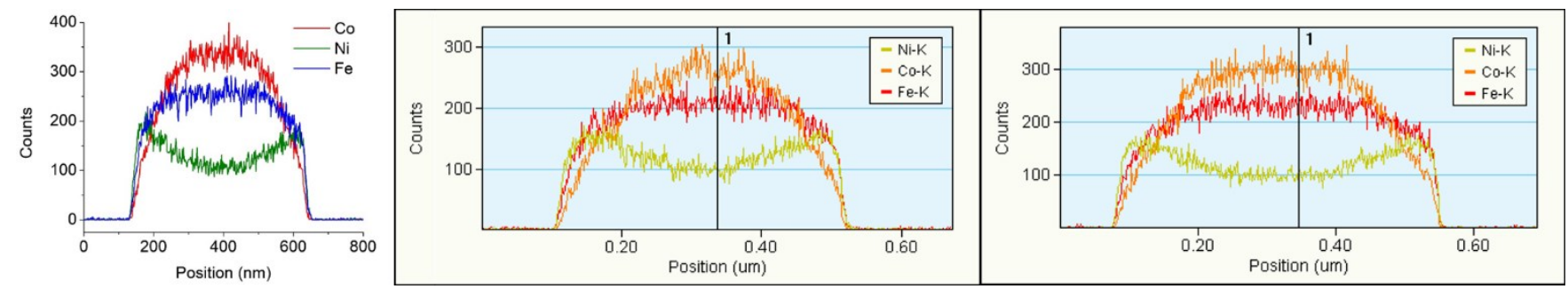

Figure S2. EDS linescan of $\mathrm{g}-\mathrm{CoNi}\left[\mathrm{Fe}(\mathrm{CN})_{6}\right]$ collected from three individual syntheses to indicate similar metal distribution. 

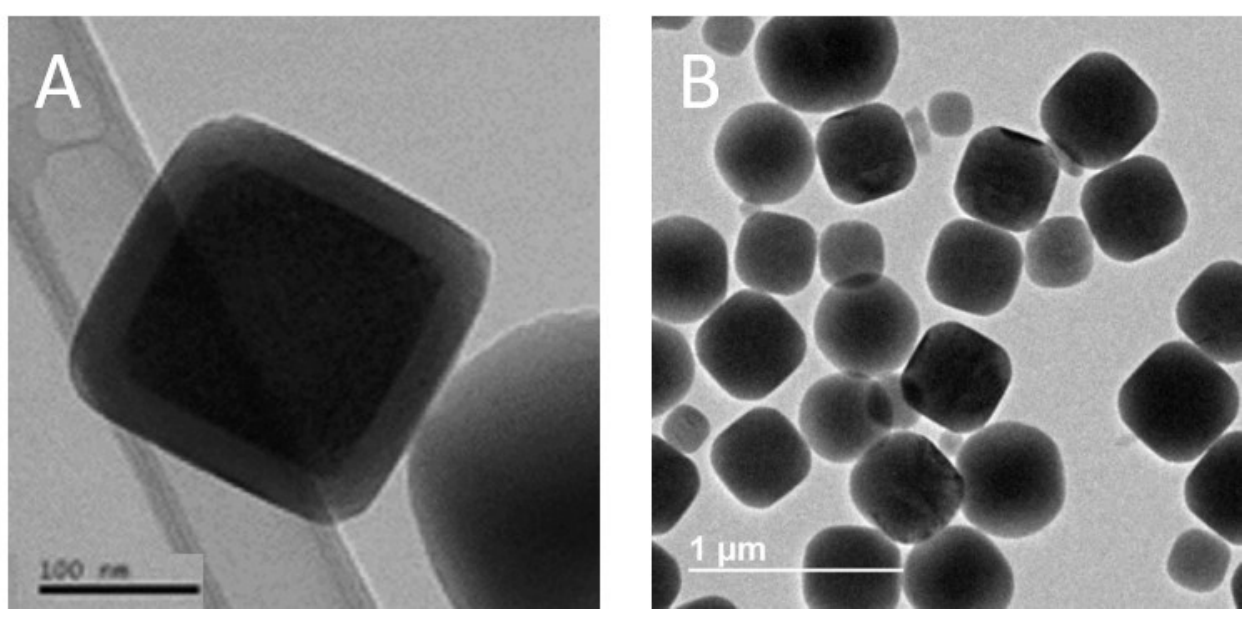

Figure S3. Representative TEM images of a core-shell (A) CoFe@NiCr particle and concentration gradient $(\mathrm{B}) \mathrm{g}-\mathrm{CoNi}\left[\mathrm{Fe}(\mathrm{CN})_{6}\right]$ particles. The core-shell image shows a clear contrast between the core and the shell separated by an interface. The change in contrast is much more gradual in the concentration gradient particles. 

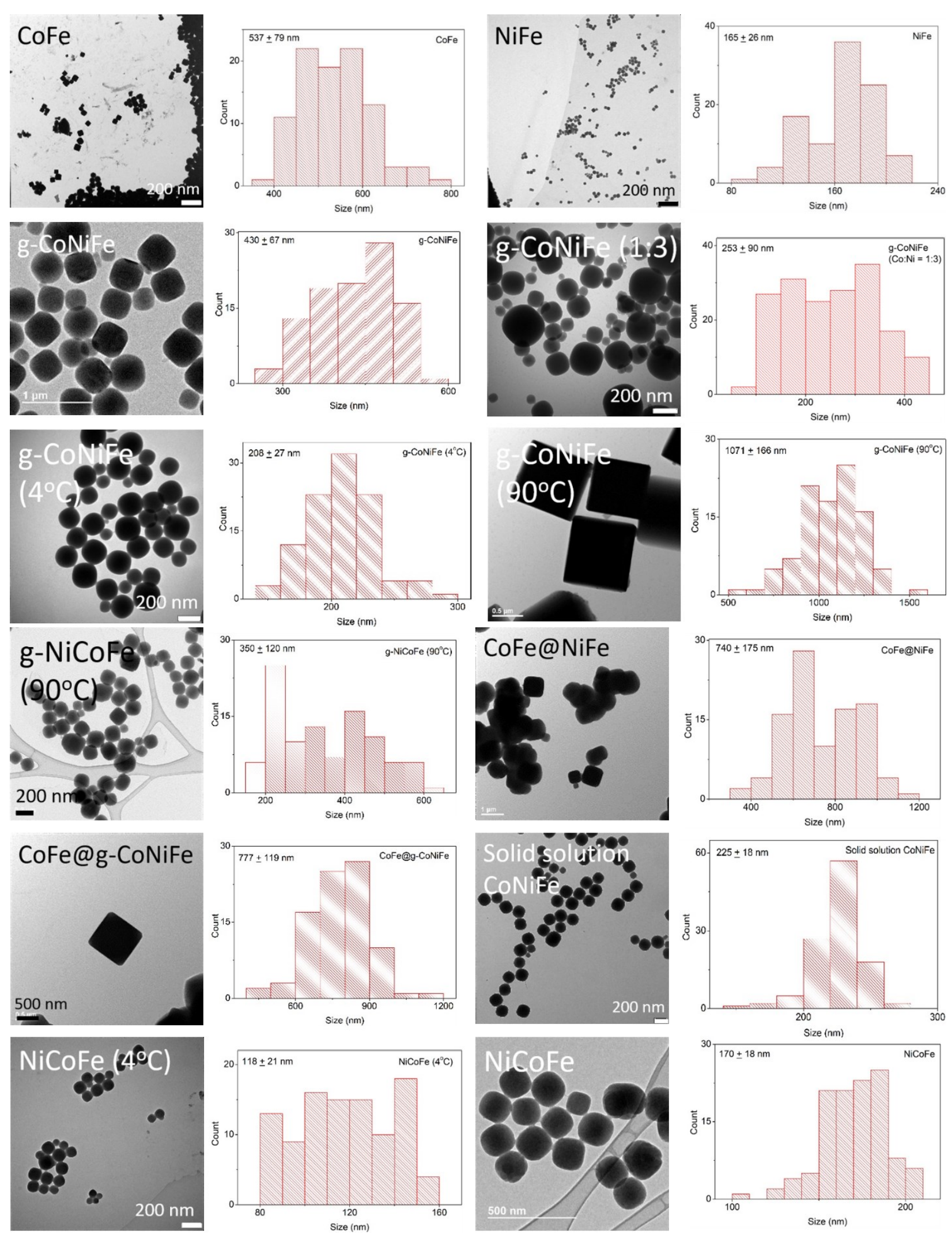
Figure S4. TEM images and corresponding size dispersions of Co/Ni samples with different architectures. Sample notations are provided on the left hand corner of each image. (Names are further abbreviated in which hexacyanoferrates are denoted as $\mathrm{Fe}$ instead of $\left[\mathrm{Fe}(\mathrm{CN})_{6}\right]$ )
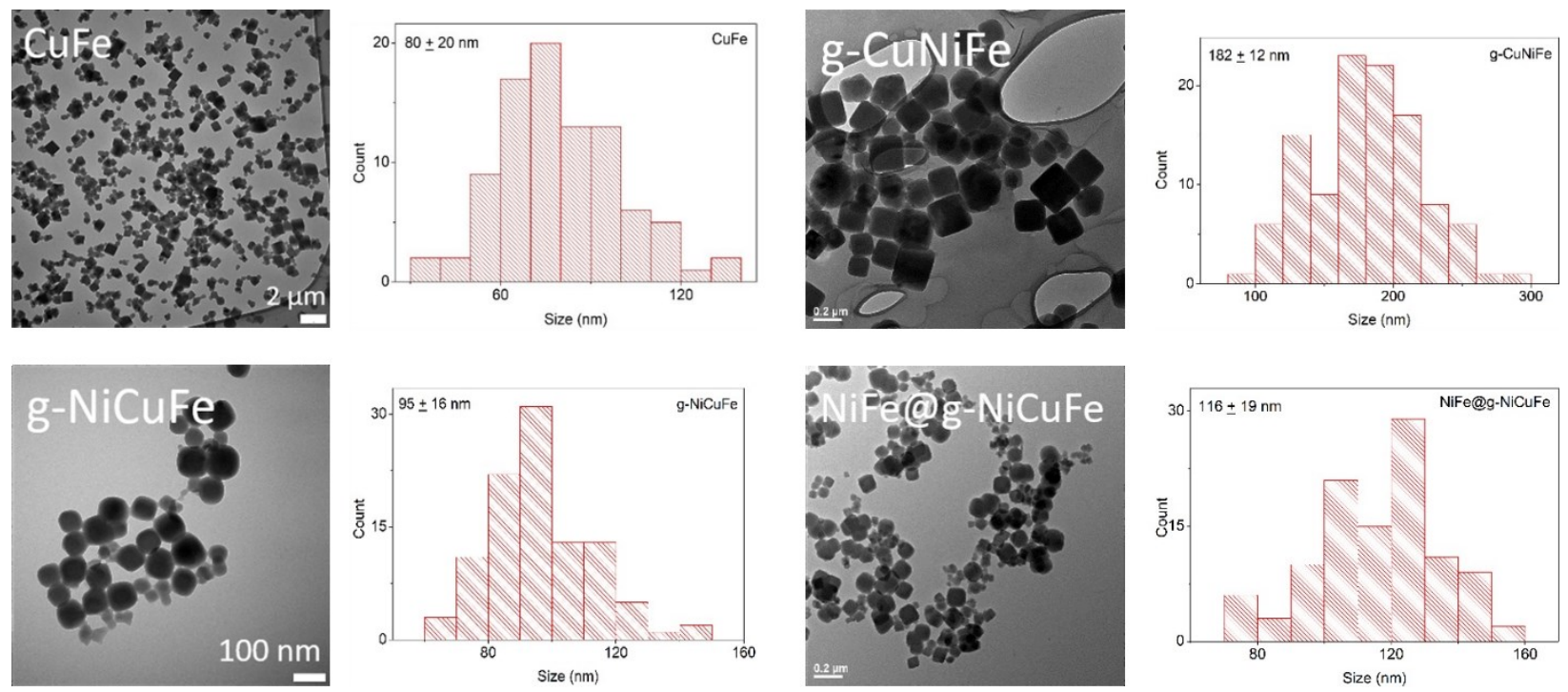

Figure S5. TEM images and corresponding size dispersions of $\mathrm{Cu} / \mathrm{Ni}$ samples with different architectures. Sample notations are provided on the left hand corner of each image. (Names are further abbreviated in which hexacyanoferrates are denoted as $\mathrm{Fe}$ instead of $\left[\mathrm{Fe}(\mathrm{CN})_{6}\right]$ )
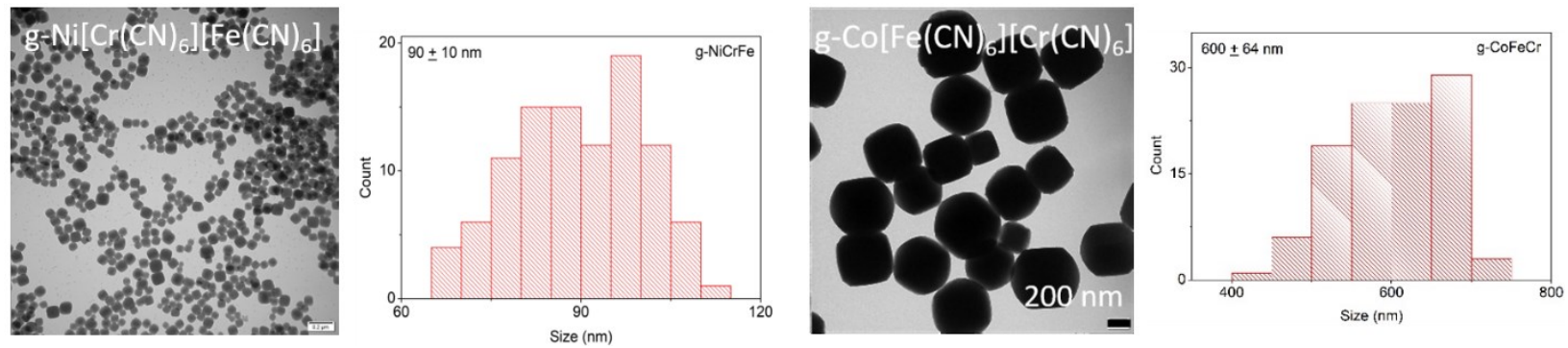

Figure S6. TEM images and corresponding size dispersions of g-Ni[Cr(CN)6][ $\left.\mathrm{Fe}(\mathrm{CN})_{6}\right]$ and g$\mathrm{Co}\left[\mathrm{Fe}(\mathrm{CN})_{6}\right]\left[\mathrm{Cr}(\mathrm{CN})_{6}\right]$. Sample notations are provided on the left hand corner of each image. 


\begin{tabular}{|c|c|c|c|}
\hline & CoFe-PBA & NiFe-PBA & CuFe-PBA \\
\hline $4^{\circ} \mathrm{C}$ & $5 \mathrm{~min}$ & $14 \mathrm{~min}$ & $\mathrm{~N} / \mathrm{A}$ \\
\hline Room temperature & $5 \mathrm{~min}$ & $12 \mathrm{~min}$ & $<1 \mathrm{~min}$ \\
\hline $60^{\circ} \mathrm{C}$ & $5 \mathrm{~min}$ & $8 \mathrm{~min}$ & $\mathrm{~N} / \mathrm{A}$ \\
\hline $90^{\circ} \mathrm{C}$ & $5 \mathrm{~min}$ & $6 \mathrm{~min}$ & $\mathrm{~N} / \mathrm{A}$ \\
\hline
\end{tabular}

Table S3. Time taken for different analogues within PBA family to show comparable light scattering, indicating precipitation in water, during Tindall effect experiments monitoring the coprecipitation reaction conditions used in this study. All the precursors were added at a constant rate of $2 \mathrm{~mL} / \mathrm{min}$ to yield $1 \mathrm{mM}$ colloidal suspension. The recorded time was determined by an emergence of beam pathway within the reaction beaker. 


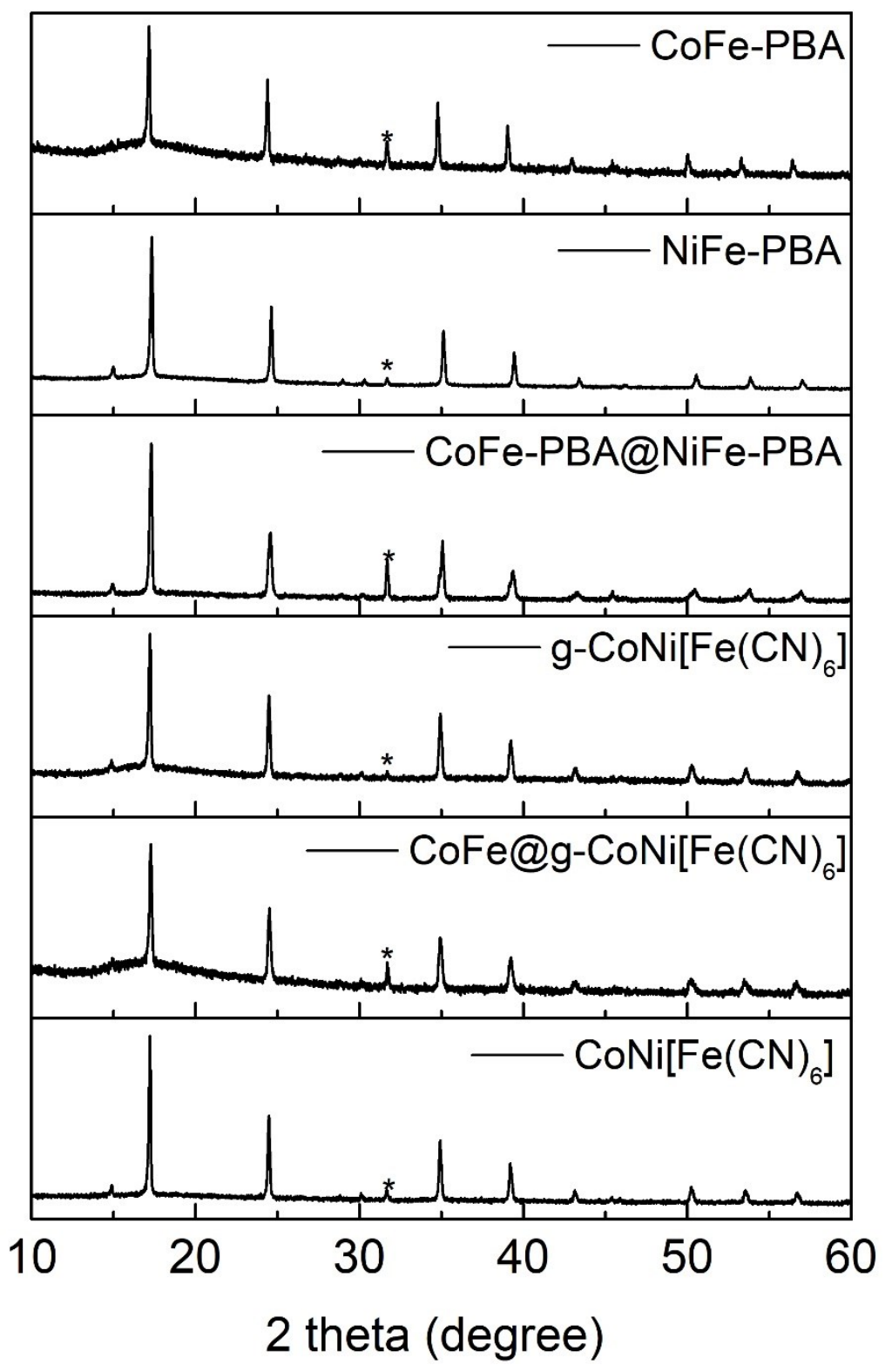

Figure S7. Full PXRD patterns of single-phase, core-shell, concentration gradient, core-gradient shell, and solid solution heterostructures. ( $\mathrm{NaCl}$ reference indicated as * in the graph) 

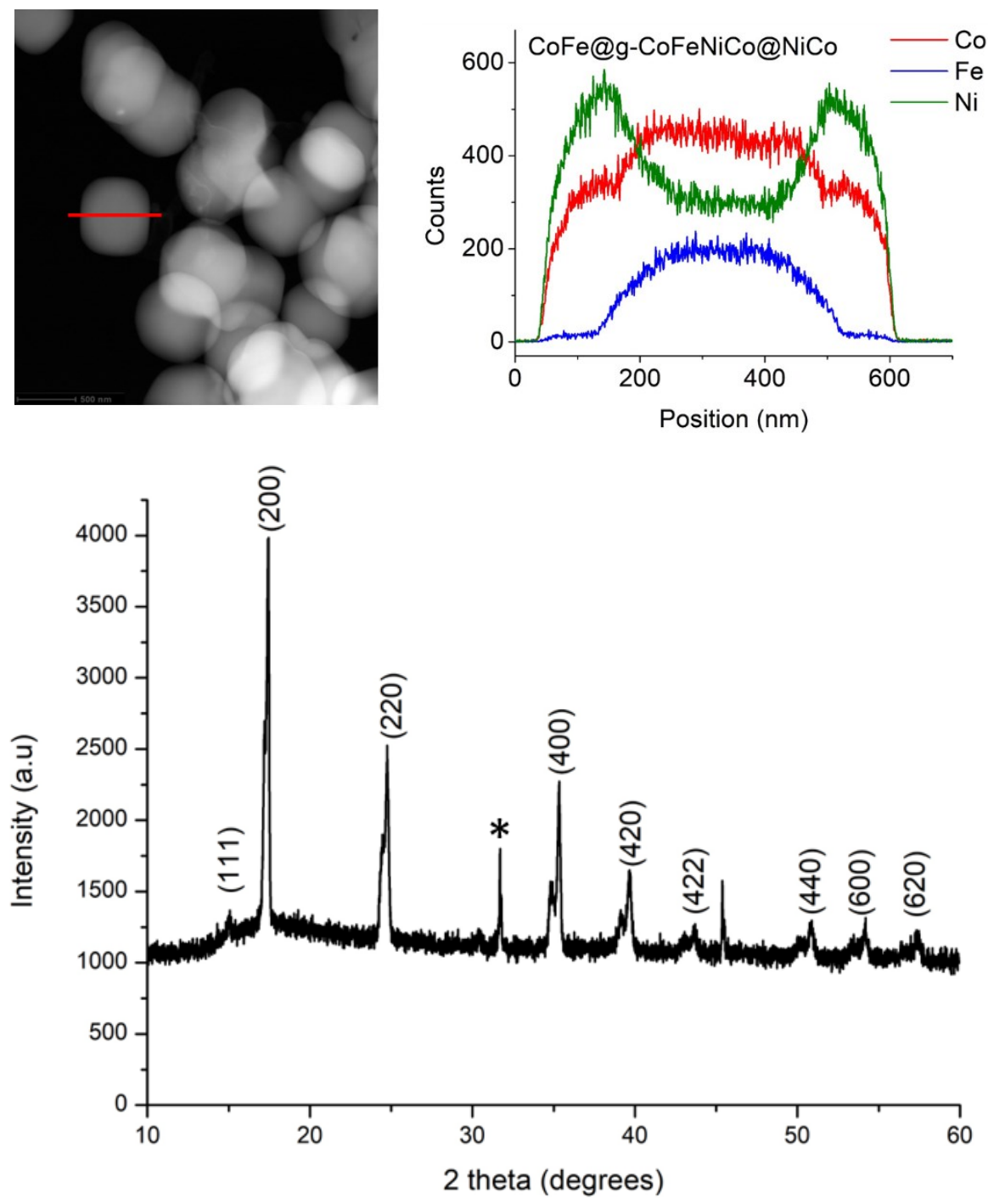

Figure S8. Corresponding TEM image and EDS linescan (above) and PXRD pattern (bottom) of core-gradient-shell of $\mathrm{CoFe} @ g-\mathrm{Co}\left[\mathrm{Fe}(\mathrm{CN})_{6}\right] \mathrm{Ni}\left[\mathrm{Co}(\mathrm{CN})_{6}\right] @ \mathrm{NiCo}$ sample. NaCl standard labeled with *. 

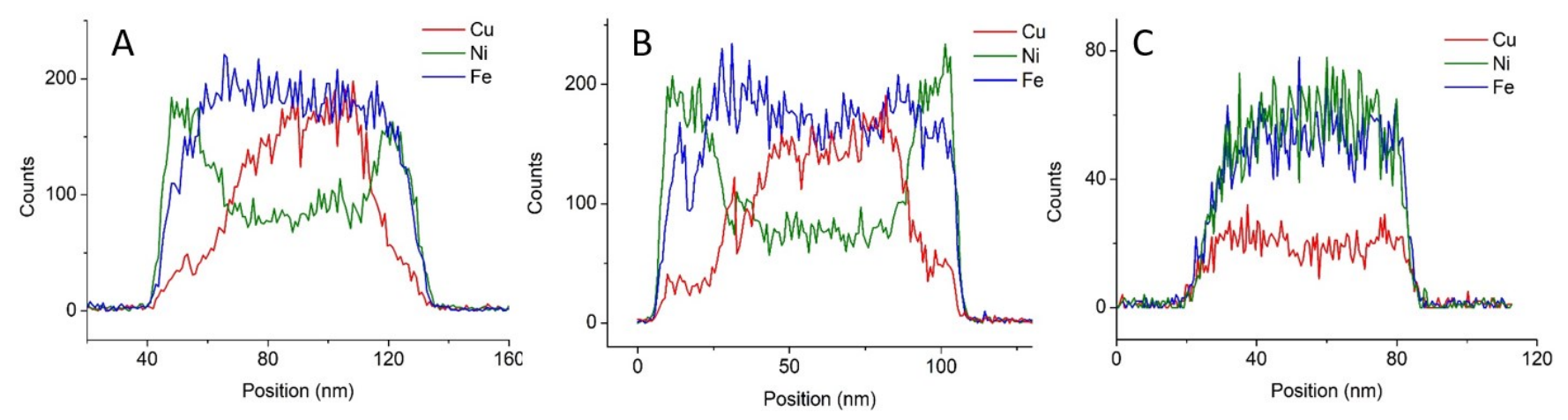

Figure S9. EDS linescans of products obtained in attempts to synthesize successful g$\mathrm{NiCu}\left[\mathrm{Fe}(\mathrm{CN})_{6}\right]$. (A) tuning the precursor addition conditions $(\mathrm{B})$ changing the reaction temperature, and $(C)$ adding chelating agents.

Three additional attempts have been conducted in order to obtain successful g$\mathrm{NiCu}\left[\mathrm{Fe}(\mathrm{CN})_{6}\right]$ system, including changing either the rate of addition or reaction temperature, adding chelating agent, and coating the gradient layer onto the pre-formed NiFe-PBA core suspension. Coming from following the same classical crystal nucleation and growth mechanism, $\mathrm{CuFe}-\mathrm{PBA}$ and NiFe-PBA have a similar effect upon changing the reaction temperature. Therefore, expedited precipitation rate of both components induce $\mathrm{Cu}^{2+}$ core-rich gradient particles via co-precipitation. Next, altering the addition conditions of precursors has been attempted. According to Tyndall effect, precipitation occurs instantaneously for CuFe-PBA, while it takes approximately 12 minutes for the NiFe-PBA precipitates to appear. Therefore, instead of starting the addition of the divalent metal precursors simultaneously, the $\mathrm{Cu}^{2+}$ precursor was allowed to start 14 minutes into the reaction. By giving a time interval between two precursors, it was initially hoped that enough time would allow for NiFe-PBA precipitates to form within the suspension to create NiFe-PBA rich core particles. However, this route still yielded gradient particles with $\mathrm{Cu}^{2+}$ core-rich gradient particles. Another possible route is utilizing sodium citrate as a chelating agent to the $\mathrm{Cu}^{2+}$ source to afford slow nucleation. Typically, the assistance of sodium citrate can coordinate to the metal ions as an initial step and effectively retard the crystallization rate of the final cyano-metal complexes. However, instead of gradient particles, homogeneous NiFe-PBA particles with partial $\mathrm{Cu}^{2+}$ substitution were detected as final products. This outcome indicated that citrate did contribute to slowing down the reaction, but an unequal ratio of two divalent metals signified an incomplete incorporation of $\mathrm{Cu}^{2+}$. The remaining unsubstituted complexes may get decanted during the washing process, yielding a lower $\mathrm{Cu}^{2+}$ proportion. The last attempt was constructing a core-gradient of NiFe-PBA@g-NiCu[Fe $\left.(\mathrm{CN})_{6}\right]$ particles. These were prepared by depositing gradient precursors onto the pre-formed NiFe-PBA cores, to inhibit $\mathrm{Cu}^{2+}$ metal ions from occupying the particle center. Unfortunately, the coexistence of $\mathrm{Cu}^{2+}$ and $\mathrm{Ni}^{2+}$ 
core-rich gradient products were observed, raising the possibility of dissolution of core particles within the suspension. As suggested by the growth pathway of NiFe-PBA, the cores can undergo an Ostwald ripening process where some of the smaller NiFe-PBA particles re-dissolve within the solution and are re-deposited onto readily formed CuFe-PBA to yield $\mathrm{Cu}^{2+}$ core-rich gradient particles. Therefore, overlapping Ostwald ripening of NiFe-PBA cores and nucleation of CuFePBA processes results in multiple by-products. As demonstrated, many efforts have been made to adjust reaction kinetics between $\mathrm{Cu}^{2+} / \mathrm{Ni}^{2+}$ precursors to yield homogeneous $\mathrm{g}-\mathrm{NiCu}\left[\mathrm{Fe}(\mathrm{CN})_{6}\right]$ particles.

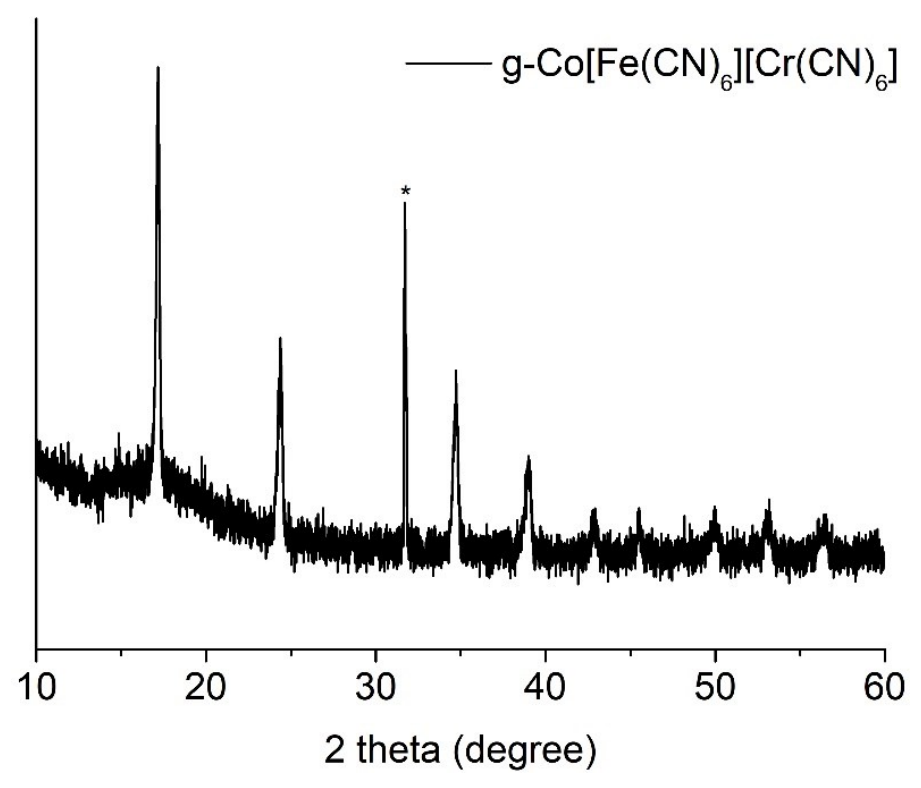

Figure S10. Full PXRD patterns of $\mathrm{g}-\mathrm{Co}\left[\mathrm{Fe}(\mathrm{CN})_{6}\right]\left[\mathrm{Cr}(\mathrm{CN})_{6}\right] .(\mathrm{NaCl}$ reference indicated as * in the graph) 